\title{
Educational Involution During the Social Transition Period
}

\author{
XUE Luyao \\ Department of English and International Studies, China Foreign Affairs University (CFAU), Beijing, 100091, China \\ ${ }^{*}$ Corresponding author. Email: gaoming@cas-harbour.org
}

\begin{abstract}
Guidelines are issued by Chinese Ministry of Education to contribute to easing burden for students undergoing compulsory education, including reducing homework and improving quality of education in details. The trend of reforms in education has postured current Educational Involution under the spotlight of the public. Whether the phenomenon could be a competitive impetus or ineffective consumption is a pending question. As a Chinese undergraduate student who is presently undergoing the inner competition, in this essay, the author is trying to analyze with personal experience the causes and drawbacks of educational involution, by reviewing published literature and comprehensively researching related information. Essentially, the existence and aggravation educational involution derive from the lag between rapidly-developing society and lagged-behind education. In accordance with both the inner and external factors, the author proposes some suggestions of solution to tackle the issue, and looks forward to the easing of the internal friction and a more sustainable educational system.
\end{abstract}

Keywords: Educational involution, China, public policy, education concept, educational system

\section{INTRODUCTION}

The academic term Involution was initially used in analyzing agriculture. This concept has then been applied to sociology, and has recently attracted widespread attention, especially in China. Yet, since current academic research on educational involution is relatively weak, and field visits and research are not possible due to the epidemic, the essay is a result of a combination of extensive searches and personal experiences. As a student who has been studying foreign languages in Chinese schools from compulsory education to higher education, the author has undergone the fierce competition and the internal friction in person. As the basis for human resource development and scientific and technological development, education occupies a fundamental and decisive position in the era of modernization. Only by developing education can a nation turn its demographic pressure into a promising talent advantage. Among all problems, it is the guarantee of educational equity that would be the most prominent. Presently, the existence and intensification of educational involution remains a major obstacle.

\section{LITERATURE REVIEW}

First introduced by Kant, Involution primarily refers to a kind of continued refinement of culture, which has a distinction with Evolution. According to Kant, the latter describes the phenomenon of seeking to perfect and adapt to the surroundings in in nature and in human society, whereas the former shows an inner repetition of selfcomplicating without having an impact on its surroundings [1]. An American anthropologist, Clifford Geertz, once used Agricultural Involution to study an economic phenomenon in his The Processes of Ecological Change in Indonesia. In Re-thinking Involution and De-involution of scholar Huang Zongzhi, Involution indicates an over-dense growth in agriculture and industry. In the case of the smallholder model of China's Yangtze River Delta or Javanese agriculture in Indonesia, once the constant investment of time and effort by the farmer on a fixed amount of land in order to increase the total amount of crops goes beyond a certain threshold, a diminishing marginal benefit exists, where the output no longer grows in proportion to the input, and even declines. The phenomenon is what is called Involution [2][3]. The concept of internal coiling was then developed by American anthropologist Alexander Goldenweiser in 1936 to describe a cultural model where 
neither the transformation into a new form nor the stabilization cannot be realized after reaching a certain form at a stage of development, instead, a repeatedly inner complication takes place [4]. Additionally, concept of State Involution brought up by Prasenjit Duara was meat to analyze state power. Similar to agricultural involution, state involution emphasizes growth without real development (i.e. without increased efficiency), regeneration and reluctance to maintain a fixed approach [5].

Whether it is related to cultural typologies, agricultural development patterns, social structures or power structures, Involution is primarily a process or state that is not simply linear and static, but a dynamic and complex retreating force referring to a low-level repetition, insubstantial or even vicious internal conflict.

\section{CURRENT SITUATION OF EDUCATIONAL INVOLUTION}

According to William Fielding Ogburn, unequal rates or degrees of change between material culture and nonmaterial culture leads to maladjustment. Specifically, when the latter trails behind the rapid development of the former, a cultural lag exists and generates social maladjustment [6]. Similarly, when the transformation of education lags behind the rapid development of society, namely, while the age of knowledge economy has arrived the schools remain in the industrial era, educational involution exists.

Although China has become the world's largest country in terms of the size of higher education, it is still far from being a power in terms of qualitative development, for the growth in size with limited resources has come at the cost of a decline in the quality. The corresponding educational resources are not increased proportionally. Schools are better equipped but less available. The education system is stagnating internally, while the overall as a whole does not improve.

The fact that the same pie has to be divided into more pieces leads to students' seeking to improve their testtaking skills via any means, to grab the limited quality resources, such as attending tutorials. However, like the theatre effect, as long as one attends a cram school, everyone will participate; as long as one school adopts the Hengshui school model, schools across the country will imitate. Everyone ends up raising the bar with more effort, and everyone is back to the same starting point. The aggravation of involution is the result of everyone's autonomous participation in self-competition. In this process, the nurturing function of education is artificially diluted or ignored.

With the promotion of policy for enrollment enlargement, the admission rate of general college enrollment has been climbing and the score line of admission has been gradually decreasing. Firstly, the expansion of the enrolment base has increased the chances of a mixed intake of new students and a decline in the overall quality of the applicants. Secondly, influenced by the market economy, a large proportion of students adopt a negative attitude towards learning, targeting their studies at obtaining a diploma with a utilitarian mindset. Such a motivation drives them to adopt an opportunistic learning approach that merely aims at getting scores, exams that are meant to evaluate their own learning consequently become a competition of marks. The pursuit of marks can also lead to repeated cheating, which can in turn affect the school's academic ethos.

Higher education remains centred on imparting knowledge and assisting students to build up a basic structure of knowledge. The long-standing emphasis on the textbook, teacher and class discipline has gradually placed students in a negative position, undermining students' independence, subjectivity and creativity. Under the spoon-feed teaching method, students passively accept knowledge mainly by memorizing, leaving aside exercising and improving their sense of innovation. The limits of theoretical knowledge are thus hard to break and the production of new knowledge cannot be realized. This mode of learning adds to pressure on students' shoulder while also exacerbates students' feelings of idleness. If the material gains after graduation do not meet their expectations, the idea of the uselessness of study may even in turn affects the social atmosphere in an absolute a negative way.

The massification of higher education has made education itself less of a scarce resource for society. More and more people are accessible to higher education with refined disciplines and the corresponding training programmes. Accordingly, evaluation criterion should be more diversified to respect the individuality of students and meet the trend of evolution in education. Nevertheless, expectations from society still equalize all the educated group with the elite by setting the selection criteria closely attached to diplomas and arbitrarily equating high academic qualification with high quality, not recognizing the trend or reality of massification of higher education. The disregard for one's overall competence is likely to lead to a mismatch between the capabilities of the individual and the position, resulting in a waste of talent. More importantly, in the long run, with this perverse talent screening mechanism being tacitly accepted and sought after, the involution expands within the whole community.

\section{DRAWBACKS OF EDUCATIONAL INVOLUTION}

The field of education can be analyzed under the theory of agricultural involution, According to Huang Zongzhi, growth refers to the increase and expansion of total production in either case, development refers to the 
growth based on increased productivity per unit of labour, and over-density means the growth of production accompanied by a decrease in productivity per unit of labour [3]. Similarly, education-wise, while the development which is based on the growth (i.e. the expansion of the scale and quantity) is in progress, the trend of educational involution in China is increasingly evident. According to Martin Trow's model theory of massification of higher education, massification itself encompasses both quantitative growth and qualitative change. The quality of higher education is bound to change accordingly when it enters the stage of massification [7]. The involution in education indicated the continuous refining and complexing within the system as a social system under the condition that it is difficult to achieve external expansion, whereas the overall effectiveness of the system has not been qualitatively developed.

Agricultural involution can lead to undesirable consequences such as the waste of resources, the same is true for the involution of education. As for students, education that is overly focused on screening functions is not only a waste of time, but also a source of great physical and mental stress. The resulting excessive or inappropriate competition can also exacerbate class entrenchment and greatly diminish the advantages of education in promoting social equity. As for parents, educating their children becomes a race to the bottom, with increasingly ineffective but obligatory investment. In the short term, financial pressure from the cost of raising children is generated, the improvement of living standards is concurrently stagnated. In the long term, the willingness of childbearing-aged families' having babies can also be consequently depressed. As for teachers and schools, the involution is a direct deviation from the original purpose of education and, by extension, from the purpose for which schools are established. It results in a convergence and rigidity of educational institutions, a decline in the quality of education and a waste of educational resources. The internal coiling also has a negative effect on society in the long run, for families' investment in education will naturally lead to a reduction in economic expenditure in other aspects, limiting people's standard of living and hindering the rate of economic growth. A large number of top talents' participation in the process of self-complicating is a great waste of talent and is not conducive to the development of productivity and the progress of other industries.

\section{ANALYSIS OF CAUSES}

\subsection{Internal Factors}

In terms of internal factors, the key lies in the different purposes of ancient and modern education. The essence can be traced back to the influence of traditional educational models and ideas. The K-12 education system enacted in present Asia dates back to the Prussians in the 18th century. It was initially created on the basis of an increase in the number of subjects and the need for a workforce with a basic education. Prior to the 19th century, both the Eastern old-style private school and the Western tutor were apprenticeships. Although the Prussian education system was innovative in many ways at the time, and succeeded in providing Germany with the vital impetus to become an industrial power, its primary purpose was to train a mass of obedient and easily managed citizens instead of cultivating them to think independently. That is where a fundamental difference lies in. It is people with higher mathematical literacy and humanistic quality that the present society demands, but not as much of a submissive and disciplined working class as it did in the past. Also, in concrete practice, Asian education system targeted at meeting the needs of manpower during industrialization, originally bear an obvious characteristic in comparison with the naturally developing Western education system. The former's frantic quest for efficiency has contributed to a more streamline-like education system. Instead of rigidly completing assignments like manual labourers, students are expected to be knowledge workers who are deemed to be the most valuable assets because of their high level of productivity and creativity, according to Peter Drucker in The Landmarks of Tomorrow [8].

Additionally, Confucianism and the imperial examination tradition permeate almost every corner of the Chinese education system in particular. Staring from the Selection of Qualified Personnel in the Spring and Autumn Period to the Imperial Examination System of the Ming and Qing dynasties, China's talent selection system has evolved and improved into a set of evaluation criteria that are more objective and standard. The Gaokao, a fundamental and irreplaceable system is considered as the fairest evaluation and selection mechanism in present China for its absolute objectivity of scores. But its drawback has been gradually recognized that scores as a sole indicator for selection is too rigid.

\subsection{External Factors}

In terms of external factors, the industrialization of education has largely exacerbated its involution. Apart from the limited resources, the key of mitigating the involution lies in the proper expectations from society and self-positioning of educational institutions. Besides, given that private institutions play an essential role in the education market, education is deeply integrated with the capital market and real estate, making educational institutions an important factor influencing the local economy and administration. The natural consequence would be that teachers and educational institutions are gradually showing a more utilitarian approach, solely focusing on incomes without passion for this industry. 


\section{SUGGESTIONS OF SOLUTIONS}

Improving the quality of education by shifting the focus from expansion is the core and key to cracking the involution of education. Attention should be attached to both academic and practical nature of education, namely, exploring knowledge while adapting to the practical needs of society [9]. The fact that China's investment level in education is below the world average requires an urgent and necessary capital financial support. Secondly, the evaluation and selection system of teachers along with the faculty should be accordingly refined, assessing not only their rigid index of scientific research ability, but also their teaching ability, as well as their ethics, professional and personal. The nature of education which is to educate needs to be further clarified, and its relationship between economy and politics needs to be properly addressed. It is a prerequisite to prevent the complete marketisation or politicization of basic education, to guarantee the independence of education and to clarify the responsibilities of public institutions. Given the differences in the nature of education for different age groups, it is of vitality to distinguish the corresponding fundamentality or competitiveness respectively. For example, in the duration of noncompetitive compulsory basic education stage, emphasis should be placed on the equal availability to educational resources. The existence of extra-curricular tuition classes deriving from commercial interests is a default at root. In terms of its motivation, the essence of its operation is to create anxiety and to satisfy anxiety, profoundly exacerbating the educational involution. As for higher education, at the point where the marginal benefits of a teaching-based approach have reached its limit, the focus should shift from teacher' teaching to students' learning, highlighting the cultivation of students' learning abilities and initiative, and the guiding regarding the right vocational values.

As an indication of urging for change and innovation, the accelerating reforms of the school system and higher education are a good start to alleviate the involution. The most fundamental lies in appreciating the nurturing process instead of the screening function. The first step is to improve the evaluation system, adopting diversified criteria rather than using scores, even a particular score, as the only indicator. For instance, the United States hold SAT scores only one of the factors considered in admissions, and there are six opportunities to take the test each year. In contrast, China's use of annual Gaokao scores as a decisive factor in college entrance can lead to students wasting too much energy on exam-oriented learning. What is more, it is high time to break the teaching method that resemble assembly-line industry and to shift from unification to individualization, respecting differences and each student's personality. Diversifying training programmes by developing targeted or multi-disciplinary courses with multiple perspectives is also effective in combating the educational involution.

\section{CONCLUSION}

Given the analysis of the drawbacks, it is easily concluded that educational evolution is ineffective consumption and inner friction rather than impetus. When burden-reduction policies were carried out, such as adopting a strict approval and supervision system for offcampus tutoring programs, doubt even opposition arose. The main argument of the opponents can be summarized as that such a one-size-fits-all policy is unfair and it hinders their children from learning more after school. However, this is fundamentally incorrect and can be argued in two points. Firstly, off-campus tutoring institutions are established on a basis of interest-oriented and profit-driven purpose, there lies a clear distinction between them and schools. Secondly, in the short term, such policy may upset children from wealthy families and their parents via cutting off the shortcuts they paved by money. Yet in the long run, chances are that major children from average or poor families will be able to stand abreast with those born with privilege at the first point.

Although the fight against educational involution is still in its infancy in China, it is appreciated that more attention is attached to this issue, and more people are joining the trend for equity in education. Only when everyone refuses to actively engage in internal competition and friction, will equality for all be truly realized.

\section{REFERENCES}

[1] W. Li, C. Yang. The grassroots autonomous involution and the structural difficulties of rural social work. Social Work, 2015(4): 22-29.

[2] C. Geertz. Agricultural Involution: The Processes of Ecological Change in Indonesia. Association of Asian Studies, Berkeley and Los Angeles: University of California Press, 2020. Doi:10.1525/9780520341821

[3] Z. Huang. Development or internal volume? Great Britain and China in the 18th century: a review of the development of the economies of Europe, China and the modern world. Int. J. Historical studies, 2002(4): 149-176.

[4] A. Goldenweiser. The Principle of Limited Possibilities in the Development of Culture. The Journal of American Folklore, 1913, 26 (101): 259290. Doi:10.2307/534816

[5] P. Duara. State Involution: A Study of Local Finances in North China, 1911-1935. Comparative Studies in Society and History, 1987, 29 (1): 132-161. 
Doi:10.1017/S0010417500014389

[6] J. Schneider. Cultural Lag: What Is It? American Sociological Review, 1945, 10(6): 786-791.

[7] M. Trow. Reflections on the Transition from Elite to Mass to Universal Access: Forms and Phases of Higher Education in Modern Societies since WWII. Springer International Handbooks of Education, Dordrecht: Springer, 2007(18). Doi: 10.1007/978-14020-4012-2_13

[8] P.F. Drucker. Knowledge-Worker Productivity: The Biggest Challenge. California Management Review, vol. 1999, 41(2): 79-94. Doi:10.2307/41165987

[9] Government expenditure on education, total (\% of GDP). UNESCO Institute for Statistics. The World Bank. Data as of September 2020. https://data.worldbank.org/indicator/SE.XPD.TOTL. GD.ZS 